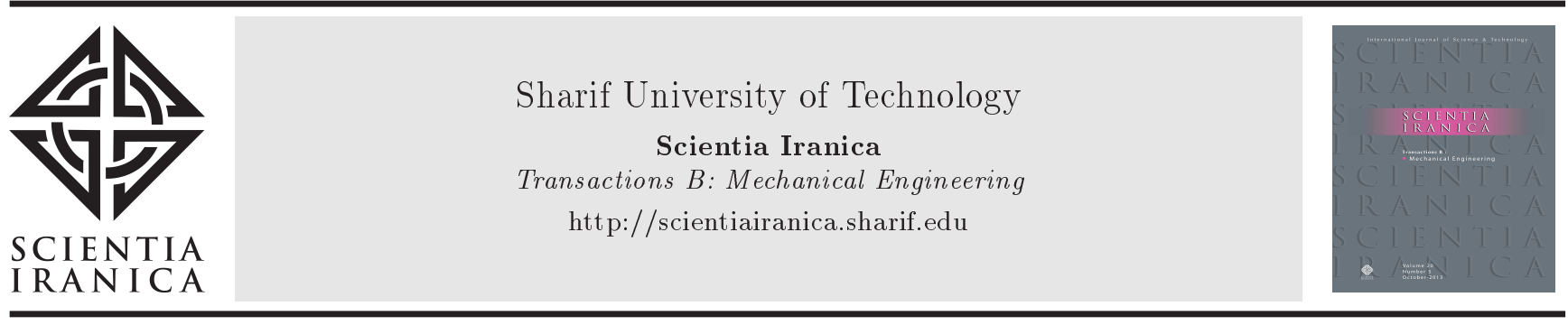

\title{
The effect of friction stir welding parameters on the microstructure, defects, and mechanical properties of AA7075-T651 aluminium alloy joints
}

\author{
J. Langari and F. Kolahan* \\ Department of Mechanical Engineering, Ferdowsi University of Mashhad, Mashhad, Iran.
}

Received 5 December 2017; received in revised form 4 February 2018; accepted 26 June 2018

\author{
KEYWORDS \\ Friction stir welding; \\ Microstructure; \\ Mechanical properties; \\ Welding defects; \\ AA7075-T651 \\ aluminum alloy.
}

\begin{abstract}
This study aims to examine how friction stir welding parameters, such as welding speed and rotational rate, affect the microstructure, defects, and mechanical properties of AA7075-T651 aluminum alloy joints. In addition, it assesses the relationship between the defects and microstructures and the mechanical properties. Microstructural investigations using Optical Microscopy (OM) and Scanning Electron Microscopy (SEM) indicated remarkable variations in grain structure among different welding zones. It was found that the interface between Welding Nugget Zone (WNZ) and Thermo-Mechanically Affected Zone (TMAZ) was a dominant determinant of the mechanical properties of joints. The significance of the interface arises from the fact that it is the most prone region to cracks, micro-cavities, and tunneling defects. The WNZ and TMAZ interfaces, as well as their grain structures, can be influenced by the heat generated from the friction between the rotating tool and work-piece material. Therefore, coarser grain structures observed at the WNZ-TMAZ interfaces of the samples welded at higher rotational rates or lower welding speeds result from the greater heat generated in such cases. Besides, microstructural variations in the weld zone affect the hardness and mechanical properties of weld joints. Thus, samples with coarse-grained structures display lower values of yield stress and microhardness.

(C) 2019 Sharif University of Technology. All rights reserved.
\end{abstract}

\section{Introduction}

Friction Stir Welding (FSW) was invented in 1991 at The Welding Institute (TWI) of UK [1]. It is a solid-state process for joining low-melting-temperature metals (such as alloys of aluminium, copper, and magnesium), which occurs at temperatures below the melting point of the materials to be joined. Unlike some joints made by fusion welding methods, the joints obtained by FSW process feature lower residual stresses,

*. Corresponding author. Fax: +985138806055 E-mail address: kolahan@um.ac.ir (F. Kolahan)

doi: $10.24200 /$ sci.2018.5700.1434 insignificant distortion, etc. [2,3]. In recent years, the unique advantages of the FSW process have given it widespread industrial applications [4]. In the case of $2 \mathrm{xxx}$ and $7 \mathrm{xxx}$ series aluminum alloys, in particular, fusion welding causes a decline in the strength and ductility in the heat affected zone. This, in turn, leads to brittle fracture, thermal cracks, porosity, and fusion defects [5]. The welding behavior of $7 \mathrm{xxx}$ series aluminum alloys deserves examination since, according to ASTM B209M-14, they are utilized in the manufacture of plates and sheets used in aerospace, military vehicles, road construction machinery, bridges, and marine and rail applications $[4,6]$.

In general, the FSW process as used for joining aluminium alloys has motivated relatively widespread 
Table 1. Chemical composition of AA7075-T651 aluminum alloy (wt. \%).

\begin{tabular}{ccccccccc}
\hline $\mathbf{Z n}$ & $\mathbf{M g}$ & $\mathbf{C u}$ & $\mathbf{C r}$ & $\mathbf{F e}$ & $\mathbf{T i}$ & $\mathbf{S i}$ & $\mathbf{M n}$ & $\mathbf{A l}$ \\
\hline 5.8 & 2.5 & 1.4 & 0.18 & 0.14 & 0.075 & 0.04 & 0.03 & Balance \\
\hline
\end{tabular}

Table 2. Mechanical properties of AA7075-T651 aluminum alloy.

\begin{tabular}{cccccc}
\hline $\begin{array}{c}\text { Tensile strength } \\
(\mathbf{M P a})\end{array}$ & $\begin{array}{c}\text { Yield strength } \\
(\mathbf{M P a})\end{array}$ & $\begin{array}{c}\text { Elongation } \\
(\mathbf{\%})\end{array}$ & $\begin{array}{c}\text { Vickers hardness } \\
(\mathbf{H V})\end{array}$ & $\begin{array}{c}\text { Poisson } \\
\text { ratio }\end{array}$ & $\begin{array}{c}\text { Elastic modulus } \\
(\mathbf{G P a})\end{array}$ \\
\hline 570 & 527 & 12.5 & 170 & 0.33 & 71.7 \\
\hline
\end{tabular}

studies. The studies deal with the effect of welding parameters on the mechanical and metallurgical properties of joints [7-8]. Mahmoud et al. [9] studied a number of parameters that affect the heat input and material flow behavior in an FSW process. The parameters include rotational rate and welding speed, vertical pressure on the tool, tool tilt angle, and tool geometry. Xue et al. [10] concluded that the tool rotational rate and welding speed were important parameters that affect the mechanical properties and microstructure of the joints resulting from FSW. Ghorbanzade et al. [11] reported that when the rate of rotation increases, AA2024-T3 alloy joints show a brittle behavior, increased strength, and decreased ductility.

Barenji [12] reported that greater welding speed enhanced the hardness and strength and decreased the elongation of defect-free joints in AA7020-T6 alloy. Rajakumar et al. [8] applied the AA7075-T6 aluminum alloy plates with a thickness of $5 \mathrm{~mm}$ and strength of $485 \mathrm{MPa}$ for FSW procedure. They showed that the main requirement for achieving desirable mechanical properties is a defect-free stir zone with a regular grain pattern and homogeneous distribution of $\mathrm{MgZn}_{2}$ precipitates. Ren et al. [13] achieved a maximum efficiency rate of $75 \%$ in the FSW of AA7075-T651 aluminum alloy plates with a thickness of $8 \mathrm{~mm}$ and a strength of $574 \mathrm{MPa}$. Their results showed that the fracture of the joint occurred in the $\mathrm{HAZ}$ region in the shear mode with an angle of $45^{\circ}$ relative to the tensile axis.

Palanivel et al. [14] used a neural network method and predicted the tensile strength of dissimilar plates joined by FSW with an error less than 5\%. They investigated the effect of welding parameters, such as rotational rate and tool pin profile, on the microstructure and defects of the joints. The influence of FSW parameters on welding defects has been the subject of a number of research studies [15-17]. In order to achieve a strong welding joint with very few defects, the parameters of an FSW process should be set at optimum values $[8,18-20]$.

In this paper, $6.3 \mathrm{~mm}$ thick joints of AA7075-T651 aluminum alloy were exposed to FSW under different parameters. The objectives of this study are: (1) to estimate the joinability of AA7075-T651 aluminum alloy under different welding parameters, (2) to determine the effect of FSW parameters (welding speed, $v$, and rotational rate, $\omega$ ) on the mechanical properties and the microstructure of the joints, and (3) to examine how the failure of the tensile specimens occurs due to defects in the FSW joints. For a detailed investigation of weld defects, SEM and OM images of the fractured surface and joints cross-sections are produced.

\section{Experimental procedure}

Rolled plates of AA7075-T651 aluminum alloy (Kamensk-Uralsky Co., Russia) were used as the joint specimens in this study. The chemical composition and mechanical properties of AA7075-T651 aluminum alloy are shown in Tables 1 and 2 .

The welding parameters were selected by consulting numerous publications, e.g., [21-24], and conducting pilot tests. As seen in Table 3 , the welding process was performed at different tool rotational rates $(\omega)$ and welding speeds $(v)$. In addition, 1.2344 hot work tool steel (Bohler W302 premium H13, Germany) with the geometry shown in Figure 1(b) was selected as the welding tool. The tool tilt angle was set at $2.5^{\circ}$ relative to the vertical axis. To obtain integrated welding, a $0.3 \mathrm{~mm}$ distance between the tool tip and the lower surface of the plates was kept during welding. The concavity of the tool shoulder caused more effective contact with the work-piece surface.

Microstructure of the base metal and as-welded samples were determined by means of Optical Microscopy (OM, Olympus GX-51) and Scanning Electron Microscopy (SEM, LEO 1450VP). The samples for

Table 3. The FSW parameters of the experiments with AA7075-T651 aluminum alloy plates.

\begin{tabular}{ccc}
\hline Sample no. & $\begin{array}{c}\text { Rotational rate } \\
(\mathbf{r p m})\end{array}$ & $\begin{array}{c}\text { Welding speed } \\
(\mathbf{m m} / \mathbf{m i n})\end{array}$ \\
\hline S1 & 630 & 20 \\
S2 & 1000 & 20 \\
S3 & 1250 & 20 \\
S4 & 1250 & 40 \\
S5 & 1250 & 60 \\
\hline
\end{tabular}




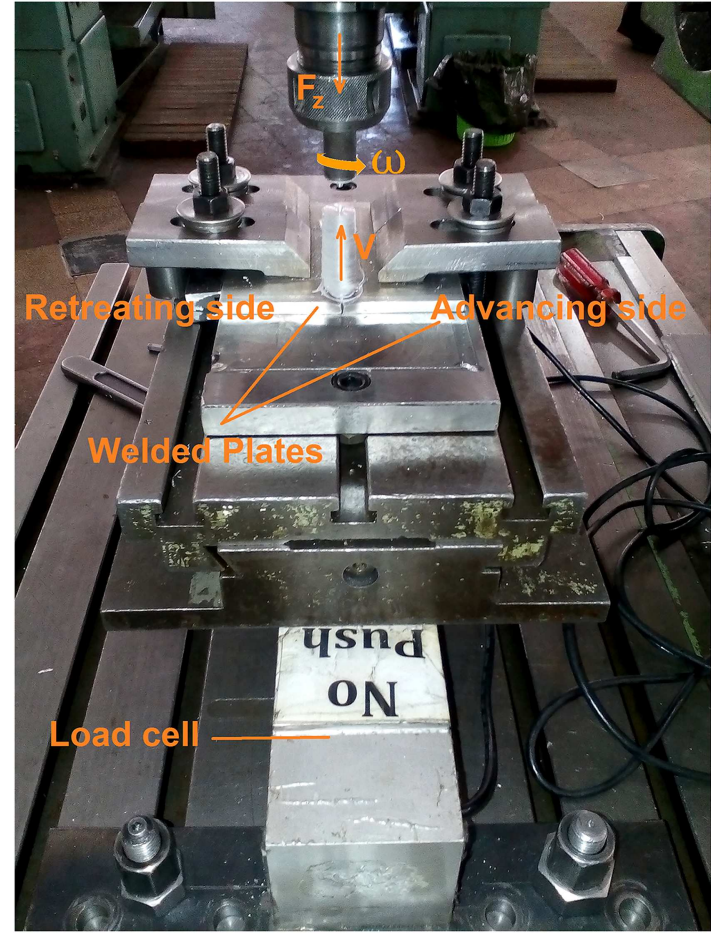

(a)

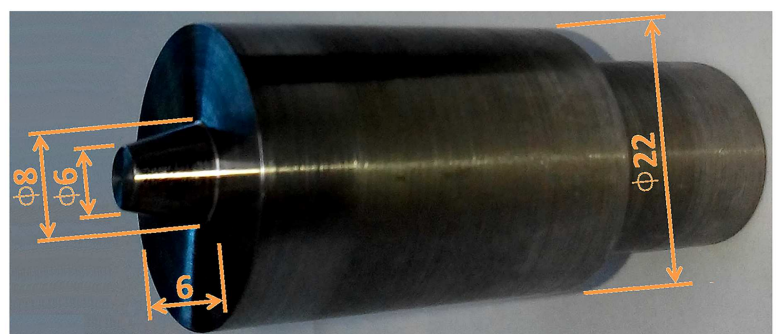

(b)

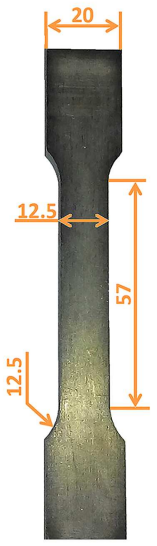

(c)

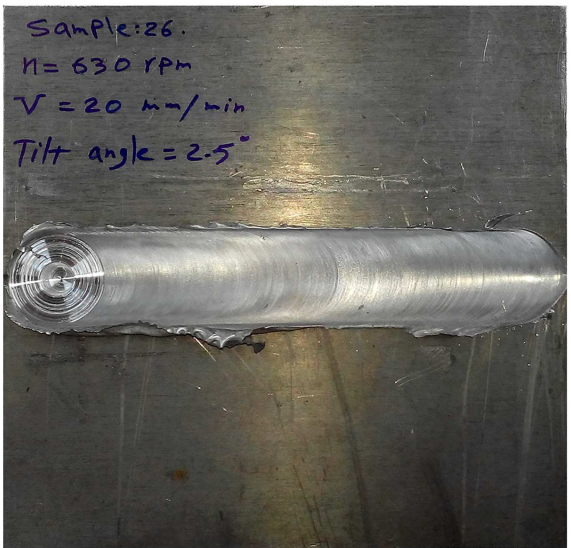

(d)

Figure 1. (a) Assembled parts for FSW. (b) Geometry of FSW tool (unit: mm). (c) Prepared tensile test specimens (unit: mm). (d) Welded AA7076-T651 aluminum alloy plates.

microstructural analyses were produced by a wire cut machine, polished by $\mathrm{SiC}$ abrasive papers, and etched by chlorine $\left(150 \mathrm{ml} \mathrm{H} \mathrm{H}_{2} \mathrm{O}, 3 \mathrm{ml} \mathrm{HNO}_{3}\right.$, and $\left.6 \mathrm{ml} \mathrm{HF}\right)$. According to ASTM E-112 standard [25], one of the most common techniques to estimate an average grain size is the intercept technique. A random straight line is drawn through the micrograph. The number of grain boundaries intersecting the line is counted. The average grain size $\left(d_{m}\right)$ in each microstructure was calculated by Clemex image analysis software using Eq. (1):

$$
d_{m}=\frac{1}{z} \sum_{i=1}^{n} \frac{L_{i}}{m_{i}},
$$

where $z$ is the number of lines, $L_{i}$ is the length of the $i$ th line, and $m_{i}$ is the number of grains located on it.

Samples for the uniaxial tensile tests were prepared in their transverse cross-sections according to ASTM: E8M-97a standard (Figure 1(c)). The tensile tests were carried out by a Zwick/Roell servo-hydraulic machine (model Amsler AB100) at a strain rate of $0.0053 \mathrm{~mm}^{-1}$, and each test was repeated three times at room temperature. In addition, Vickers microhardness tests were performed in different weld zones according to ASTM: E384-11e1 standard. The microhardness of the samples was measured in the middle of their transverse cross-sections at an interval of $1 \mathrm{~mm}$, while they were under 200-gr loading at a 10-second dwell time.

\section{Results and discussion}

\subsection{Microstructural analysis}

A typical SEM micrograph of 7075-T651 aluminum alloy and a cross-sectional image of one of the FSW joints are shown in Figure 2(a) and (b), respectively. Four distinct zones are recognized in the cross-sectional microstructure of an FSW joint. According to the granular microstructure of the FSW joint in Figure 2(b), we distinguished the zones of Base Metal (BM), Heat Affected Zone (HAZ), Thermo-Mechanically Affected Zone (TMAZ), and Weld Nugget Zone (WNZ). OM images obtained in different zones (Figure 2(c)-(e)) suggest significant microstructural variations across the range spanning from WNZ to BM sections. While BM microstructure consists of large elongated grains with a homogenous distribution of $\mathrm{Al}(\mathrm{Zn}, \mathrm{Mg}, \mathrm{Cu})$ precipitates, the microstructures of the three other weld zones were affected by the weld heat, which proportionally brought about the dissolution of precipitates and created porosities and variations in the grain structures. More importantly, we distinguished the interfaces between WNZ and TMAZ as a notable region in the weld section. Aggregation of porosities in the interfaces and the great variations in the grain structures 

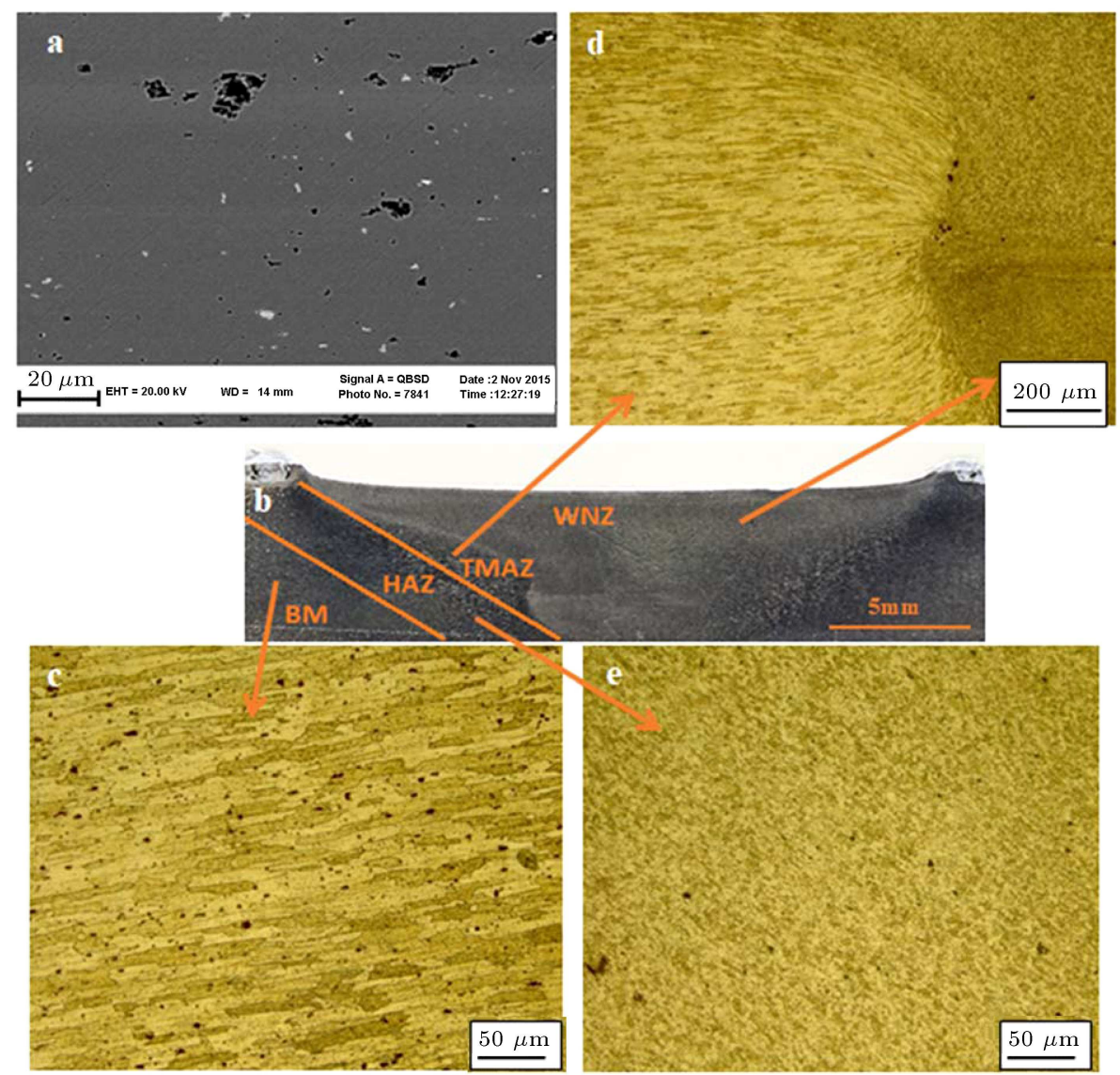

Figure 2. (a) An SEM micrograph of 7075-T651 aluminum alloy. (b) Cross-sectional image of weld zones in S1 sample. (c)-(e) OM micrograph of S1 weld sample in different weld zones.

in the weld section make the interfaces the dominant failure sections. The choice of suitable parameters can decrease the defects, leading to the modification of the microstructures of the WNZ and TMAZ zones. This technique may be effective in improving the mechanical properties of the joint samples $[12,26]$.

Since FSW is a solid-state joining process, WNZ and TMAZ interfaces, as well as their grain structures, can be influenced by the heat generated by the friction between the rotating tool and the workpiece material. Cross-sectional micrographs of S1 to S5 joints (Figure 3 ) confirmed that the FSW parameters of rotational rate and welding speed led to changes in the microstructures of the weld zones. These results indicated that heat input was influenced by the FSW parameters of rotational rate and welding speed. Further, if there is insufficient or excessive heat input in the FSW process, prepared joints are prone to welding defects such as pinhole, tunneling, cavity, kissing bonds, and cracks $[12,26]$. Thus, we recognized welding defects such as a cavity in S3 and S4 samples (Figure 3(c) and (d), respectively) and tunneling defect in S5 joint (Figure 3(e)). These results suggested that welding defects were more likely to appear when rotational rate and welding speed were higher.
High magnification OM and SEM micrographs of WNZ-TMAZ interfaces are clearly seen in Figure 4. It indicates that, in addition to tunneling and cavity defects, small cracks are also present in the WNZ-TMAZ interfaces of the samples welded at higher rotational rates. More detailed SEM investigations reveal that the above-mentioned cracks are actually originated from the integration of numerous microcavities aggregated in this area. Generation of tunneling, cavity, and crack defects in the WNZ-TMAZ interfaces of the samples welded at higher rotational rates (Figure 4(c), (d), and (e)) can be attributed to the inadequate material flow. Besides, SEM investigations indicated that lower rotational rates were not suitable for the FSW process since inadequate heat input could lead to the generation of microcavities in the WNZ-TMAZ interfaces (Figure 4(a)). These results suggested that the tool rotational speed must be low enough to facilitate material flow and be high enough to increase the frictional heat in the weld zone. Therefore, defectfree WNZ-TMAZ interfaces can be obtained through the FSW process at a rotational speed of $1000 \mathrm{rpm}$ and a welding speed of $20 \mathrm{~mm} / \mathrm{min}$. Considering the five fabricated joints and using various welding parameters, the aforementioned fabricated joint exhibited superior 


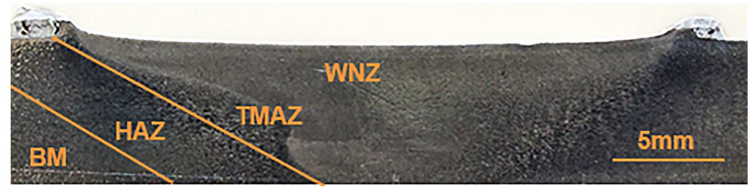

(a)

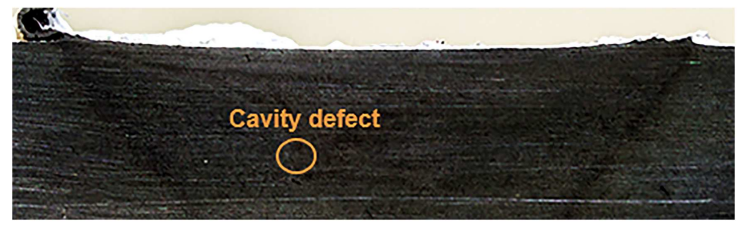

(c)

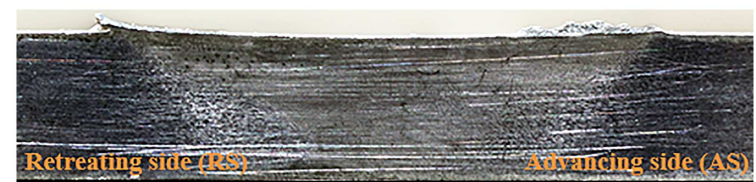

(b)

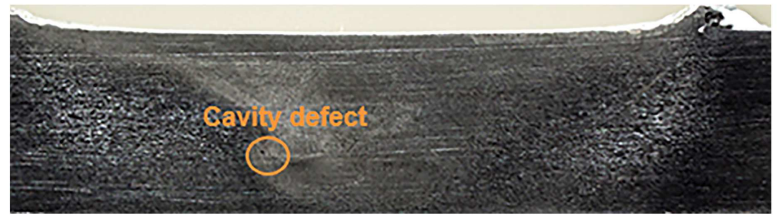

(d)

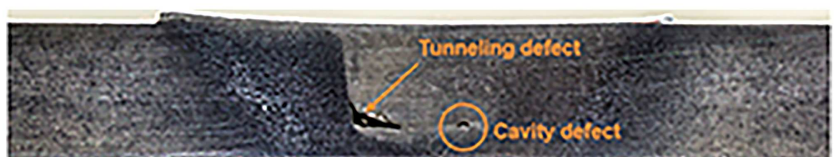

(e)

Figure 3. Cross-sectional micrographs of different weld zones in S1 to S5 joints.

mechanical and metallurgical properties in comparison to other fabricated joints (Figure $4(\mathrm{~b})$ ).

Differing grain structures were also observed on the WNZ and TMAZ sides of the welded samples, as shown in Figure 4. While the existence of fineequiaxed grains implies dynamic recrystallization phenomenon in WNZ area [27], the TMAZ microstructure is in agreement with the elongated grain pattern along a flow perpendicular to the WNZ -TMAZ interface $[26,28]$.

The shape and size of grains in the weld zones can be extremely affected by the heat input and cooling rate of FSW processes. In this study, the effects of different heat inputs on the microstructure of the weld samples at a constant cooling rate were investigated.

Frigaard et al. [29] introduced the following equation for the effect of rotational rate $(\omega)$ on the heat input $(q)$ generated by an FSW process:

$$
q=\frac{4}{3} \pi^{2} \mu P_{z} \omega r^{3},
$$

where $\mu, P_{z}$, and $r$ denote the friction coefficient, tool pressure, and radius of shoulder, respectively. Further, the relation expressing the effect of welding speed $(v)$ on heat input per unit length $(Q)$ was suggested by Kim et al. [30] as follows:

$$
Q=\frac{\eta q}{v}=\frac{4}{3} \pi^{2} \frac{\eta \mu P_{z} \omega r^{3}}{v},
$$

where $\eta$ is the heat input efficiency.

Considering constant values for $\eta, \mu, P z$, and $r$, heat input per unit length $(Q)$ versus rotational rate $(\omega)$ and welding speed $(v)$ can be written as follows:

$$
Q=\beta \frac{\omega}{v},
$$

where $\beta=\frac{4}{3} \pi^{2} \eta \mu P_{z} r^{3}$.

According to Eq. (4), heat input increases with rotational speed (QS1 < QS2 < QS3) and reduces with welding speed (QS3 > QS4 > QS5). Since greater heat inputs lead to the growth of recrystallized grains, higher rotational rates or lower welding speeds are expected to increase the average size of grains in the WNZ, TMAZ, and even HAZ areas. The weld nugget zones of the samples welded with various heat inputs are shown in Figure 5 through SEM micrographs of two different magnifications. Based on the results of image analysis, the average grain size increased from 4.4 to $5.8 \mu \mathrm{m}$ in the samples welded at a constant welding speed of $20 \mathrm{~mm} / \mathrm{min}$, while the rotational rate increased from 630 to $1250 \mathrm{rpm}$ (Figure 5(a), (b), and (c), respectively). In addition, at a constant rotational rate of $1250 \mathrm{rpm}$, the average grain sizes were 5.8, 4, and $3.7 \mu \mathrm{m}$ for the samples welded at welding speeds of 20,40 , and $60 \mathrm{~mm} / \mathrm{min}$, respectively.

\subsection{Microhardness}

Microstructural variations in the weld zone are expected to affect the hardness and mechanical properties of the weld joints. The microhardness of the weld zone gradually decreased from $170 \mathrm{HV}$ in BM to about $100 \mathrm{HV}$ in WNZ. The reduction of microhardness can be attributed to grain growth and precipitates dissolution in the heat-affected weld zones [12,27,31-33]. A drop in microhardness was observed in the WNZTMAZ interfaces of some samples. The unexpected drops result from some defects in the WNZ-TMAZ interfaces and coarser grain structures in TMAZ (Figure 4).

The variations in the microhardness of a typical sample involving a variety of grain structures can be 

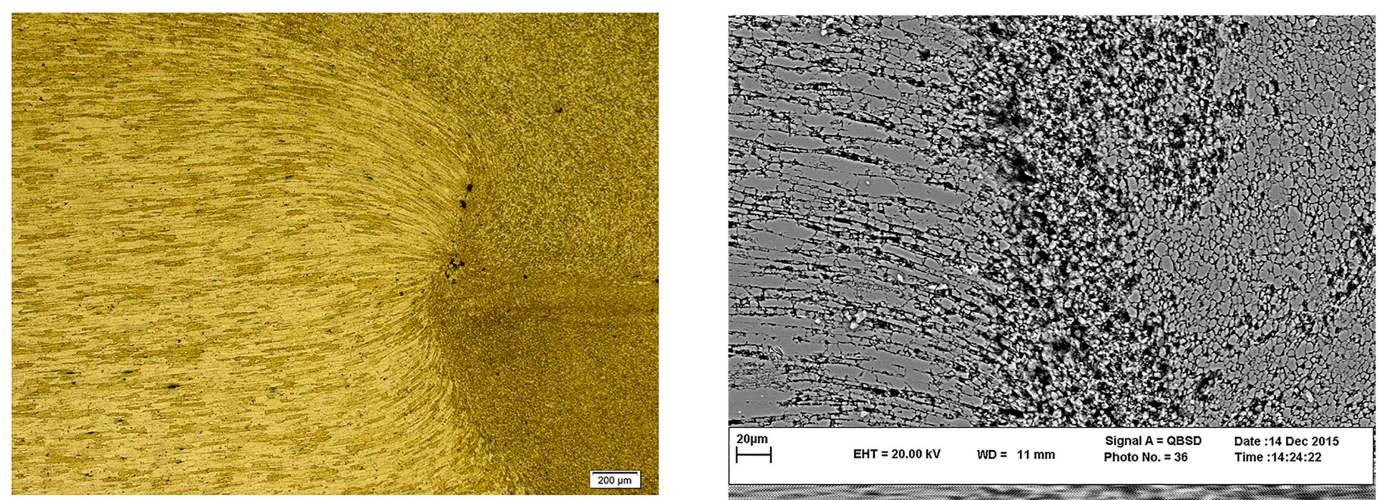

(a)
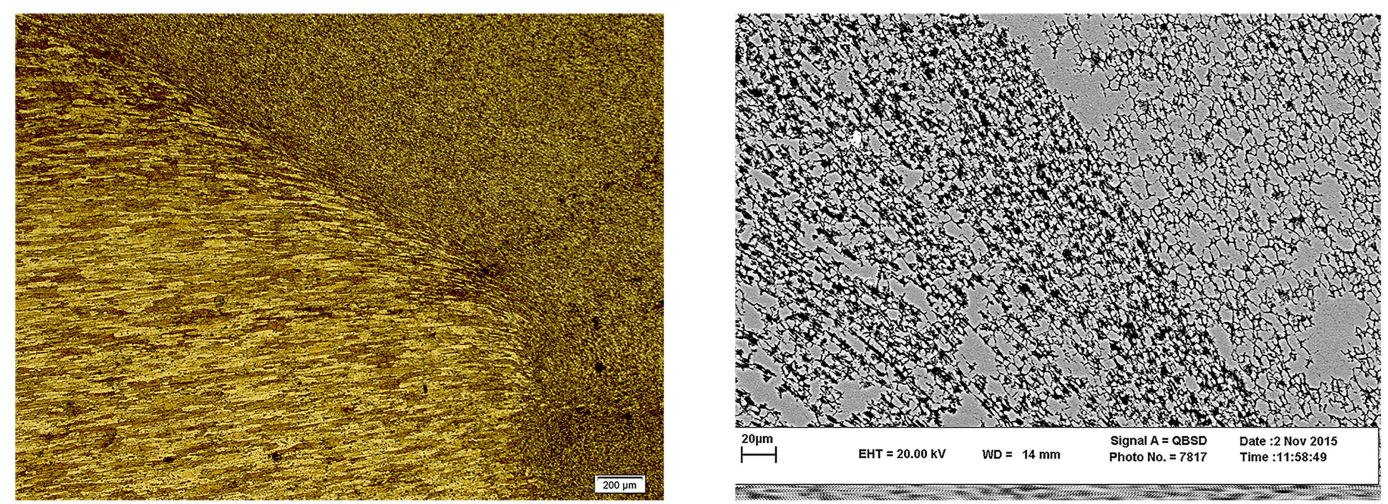

(b)
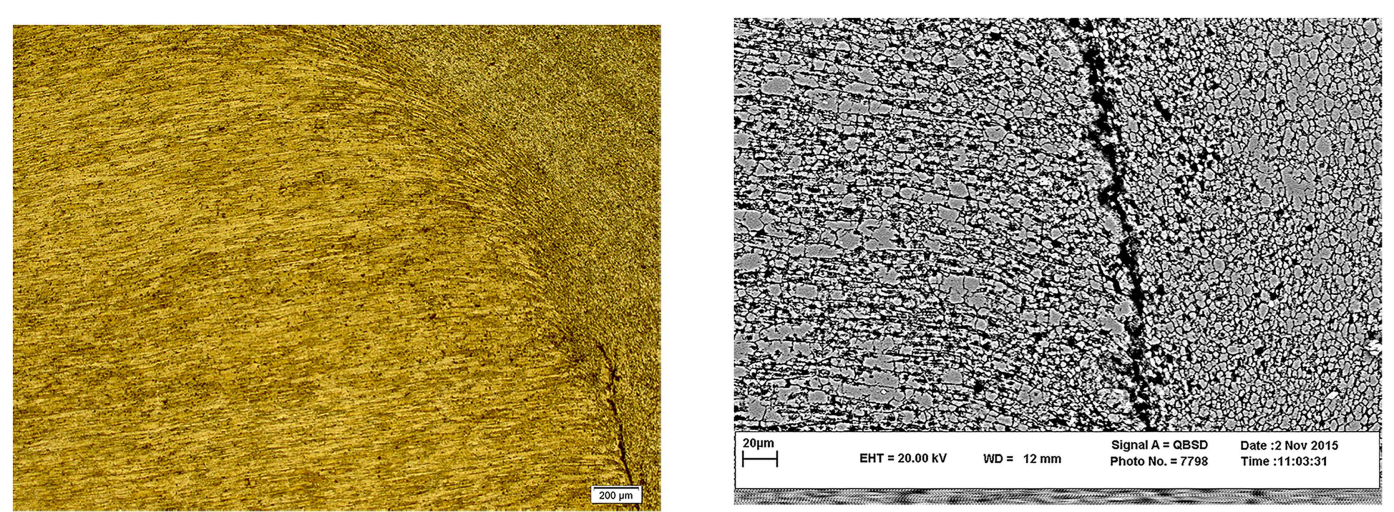

(c)
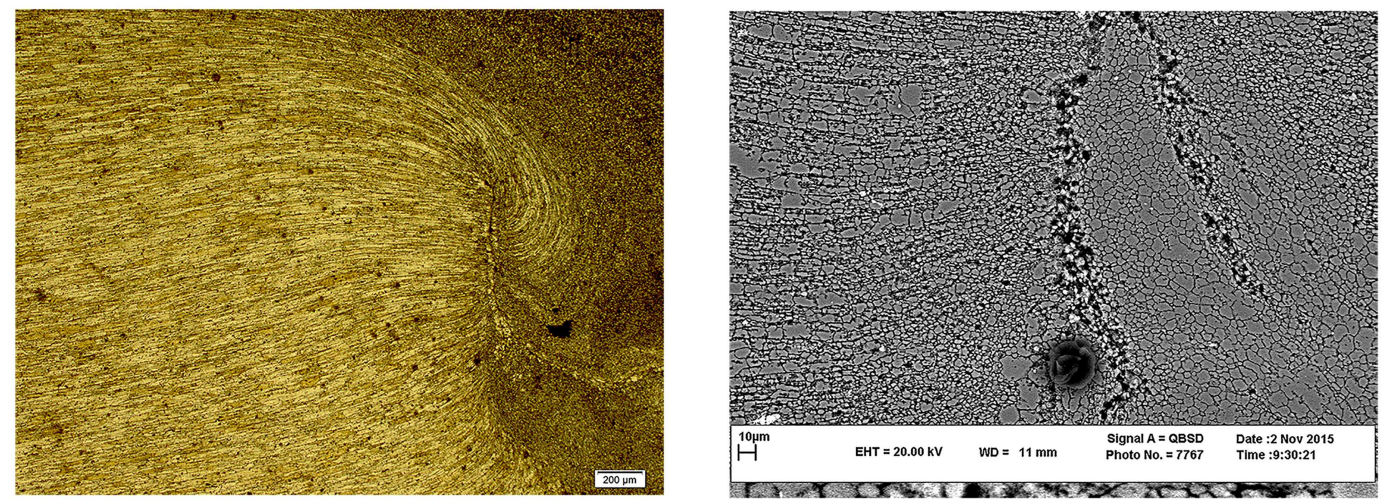

(d)

Figure 4. OM and SEM micrographs of WNZ-TMAZ interfaces in S1-S5 samples (a) to (e), respectively. 

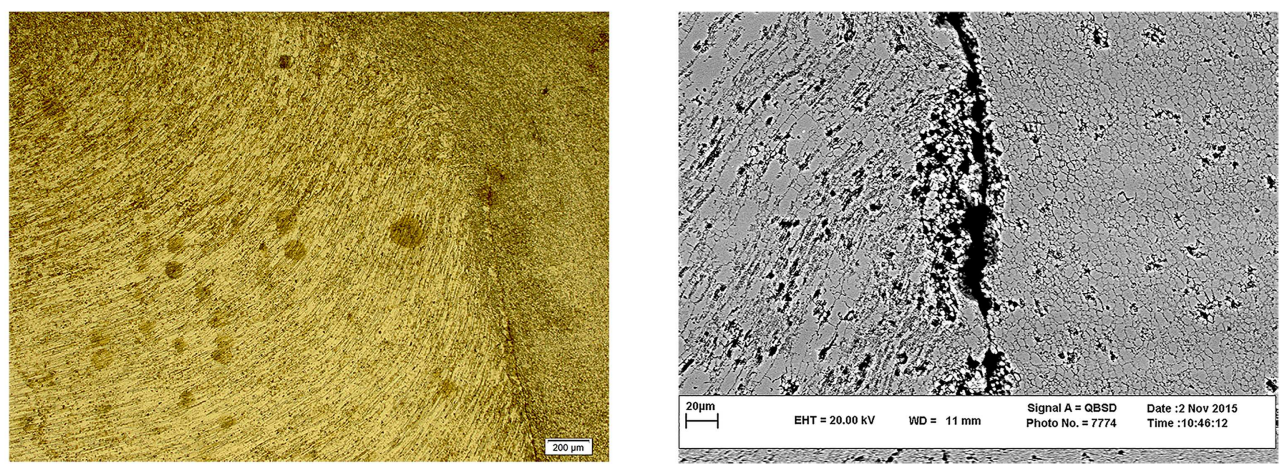

(e)

Figure 4. OM and SEM micrographs of WNZ-TMAZ interfaces in S1-S5 samples (a) to (e), respectively (continued).

explained by Hall-Petch strengthening mechanism [34]. According to the mechanism, grain boundaries impede dislocation motions. Therefore, any decrease in the number of grain boundaries (resulting from grain growth) can lead to a microhardness reduction. Based on the Hall-Petch strengthening mechanism, higher microhardness values are expected for the samples with smaller grain sizes, including those welded at lower rotational rates or higher welding speeds. A comparison of the values of microhardness confirms that, at a constant rotational rate of $1250 \mathrm{rpm}$, higher welding speeds led to increased microhardness of weld zones (Figure 6(a)). Besides, lower rotational rates, which result in smaller grain sizes, led to higher microhardness values (Figure 6(b)). The hardness indicates the asymmetrical distribution in the weld centerline, and the maximum hardness is observed on the advancing side, not on the weld center. The reason is the plastic flow field of the two sides of weld center, which is not uniform [35-37]. The piling of materials on the advancing side is more noticeable than that on the retreating side. The larger distorted grains and distortion energy associated with strain-hardening increase considerably, leading to the asymmetrical microhardness distribution.

\subsection{Tensile properties}

Figure 7 illustrates the tensile test stress-strain curves of the as-welded samples and 7075 aluminum alloy at room temperature and at a strain rate of $0.00531 / \mathrm{min}$. By applying the stress-strain curve, the values of yield stress, tensile strength, and elongation of the samples were obtained, and the results are reported in Table 3. According to our expectations, yield stress variations are in agreement with the observed grain growth trend. The relation between yield stress and grain size is mathematically described by the HallPetch equation [34]:

$$
\sigma_{y}=\sigma_{0}+\frac{k_{y}}{\sqrt{d}}
$$

where $\sigma_{y}$ is the yield stress, $\sigma_{0}$ is a material constant denoting the stress triggering dislocation movement, $k_{y}$ is the strengthening coefficient, and $d$ is the average grain diameter. The relationship of yield stress to WNZ mean grain size agreed well with the predictions of HallPetch mechanism, and indicated that the yield stress of the welds decreased at higher rotational rates or lower welding speeds, i.e., the process conditions that caused greater grain growth.

The results in Table 4 also suggest that the ultimate tensile strength decreased for the samples welded at higher rotational rates and welding speeds. Lower ultimate tensile strength of S4 and S5 samples can be explained by the crack and tunneling defects in the WNZ-TMAZ interfaces. Joint efficiency, defined as the ratio of the ultimate tensile strength of the joint to that of base metal [38], ranged from $58 \%$ to $71 \%$ in this study. In addition, the elongation values of the joints were in the range $1.15-5.27 \%$, which are much lower than that of the base metal. In accordance with other reports in the literature, smaller elongation of joints can be related to the presence of tunneling, cracks, and microcavity defects in the WNZ-TMAZ interfaces and subsequent stress localization in those regions [39].

The fracture surfaces of the base metal and FSW joints, at different magnifications, are shown in Figure 8. According to the cross-sectional images of the tensile tests failures, fracture occurs in the middle region of all the samples, where stress is localized at the defects in the WNZ-TMAZ interfaces. The failure angle of $45^{\circ}$ relative to the direction of the tensile axis suggested that the fracture, in both the base metal and FSW joints, occurred in the shear mode. The existence of deep, shallow, and sheared dimples and cleavage planes observed in the SEM fractographs is in agreement with ductile fracture mechanism. A decrease in the rotational rate led to a drop in the number of the dimples. Besides, the samples welded at a rotational rate of $630 \mathrm{rpm}$ displayed a behavior suggestive of combined ductile-brittle fracture mechanisms (Figure 8). 

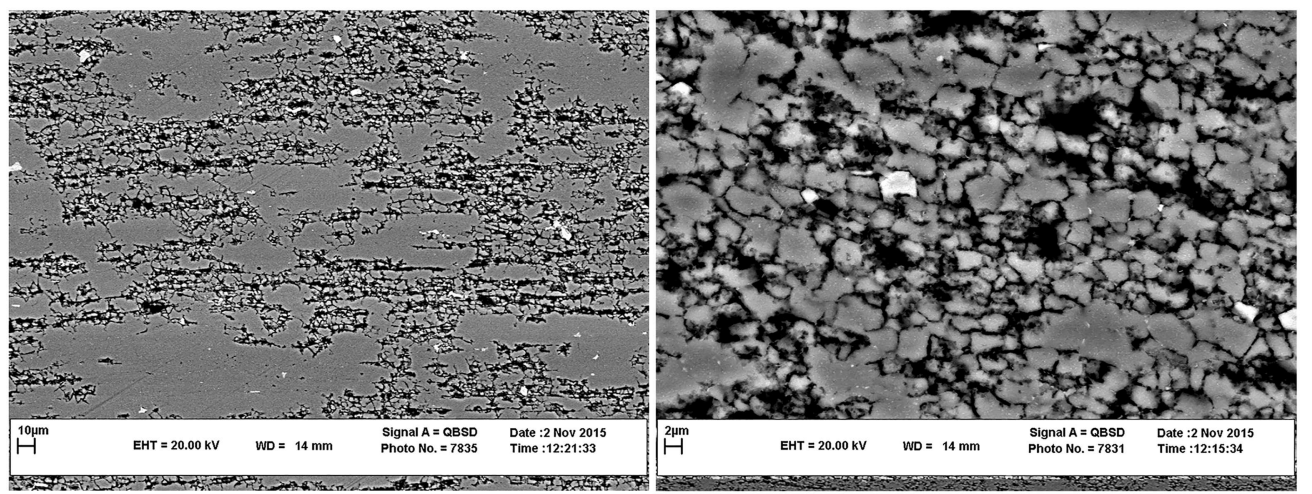

(a)
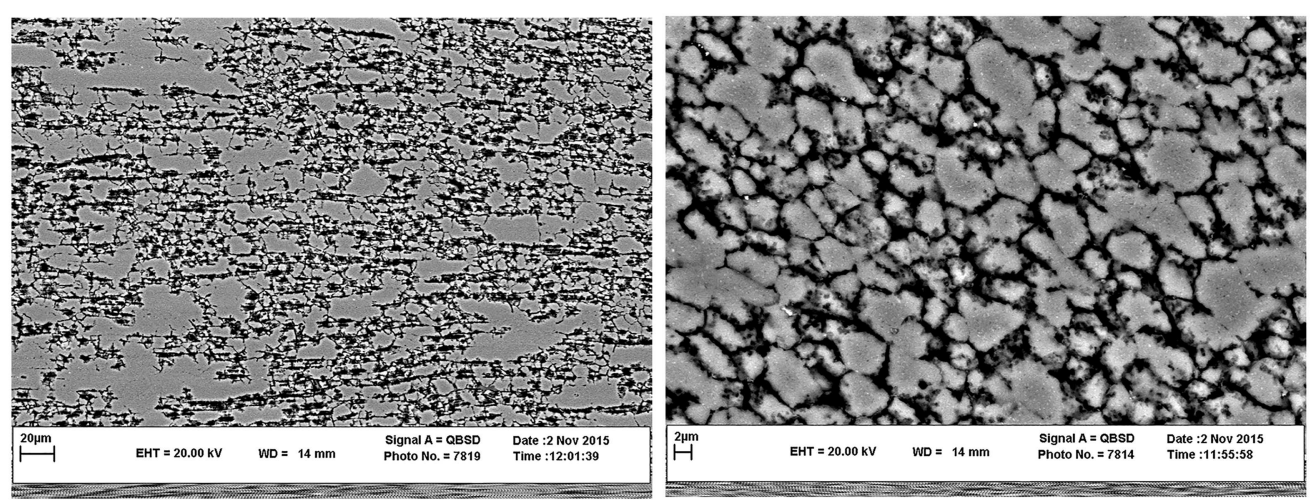

(b)
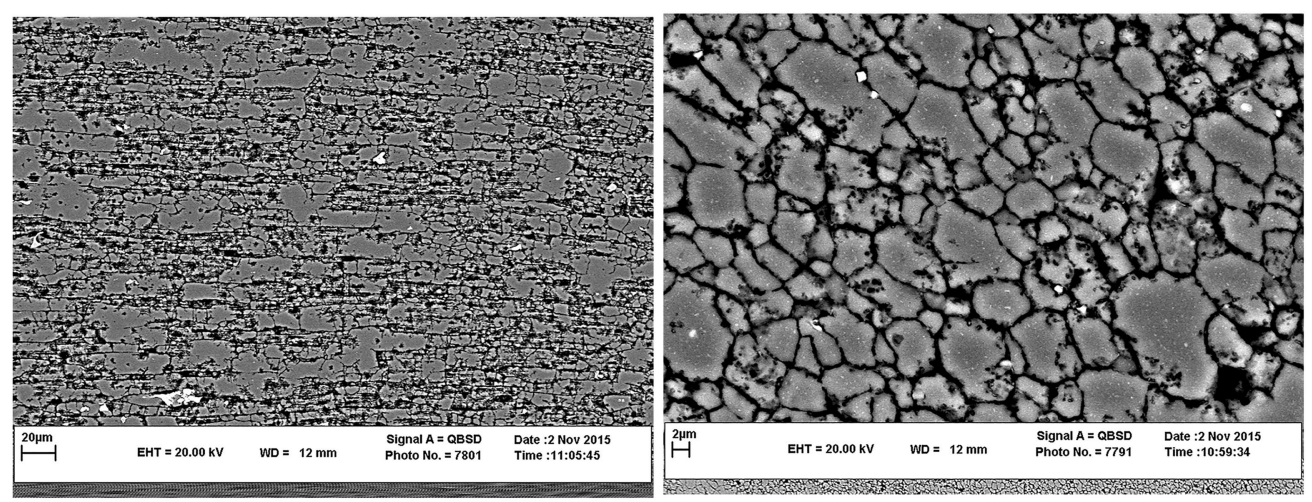

(c)
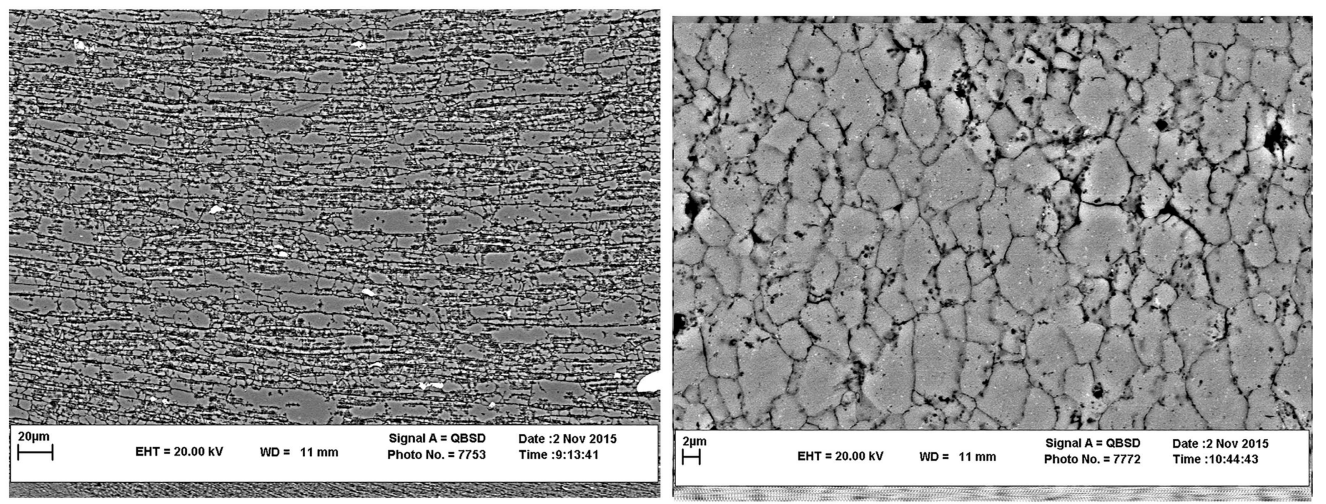

(d)

Figure 5. SEM micrographs of the WNZ region in the S1-S5 samples with different magnifications (a) to (e), respectively. 

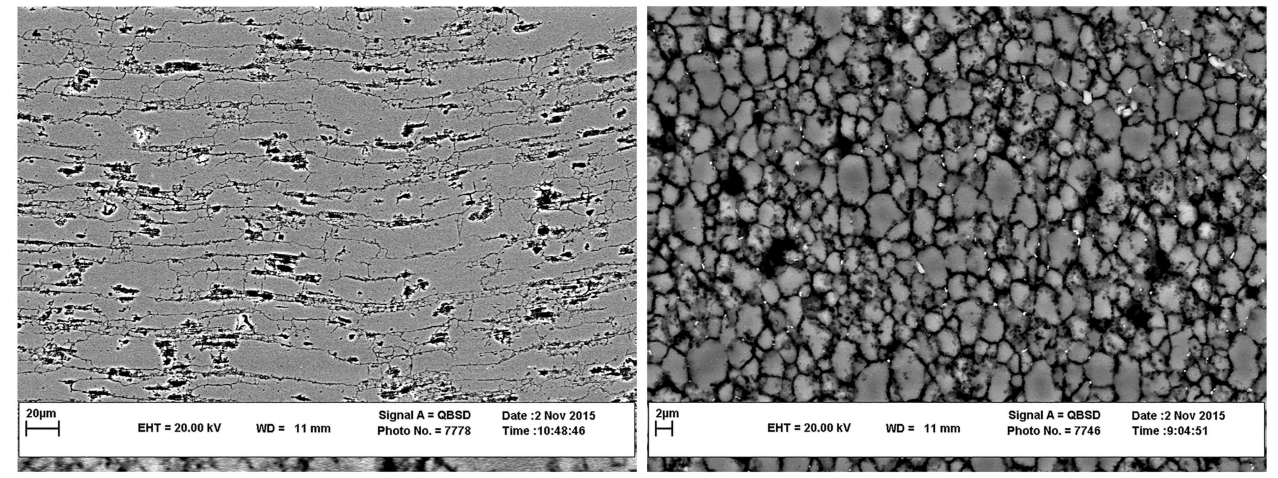

(e)

Figure 5. SEM micrographs of the WNZ region in the S1-S5 samples with different magnifications (a) to (e), respectively (continued).

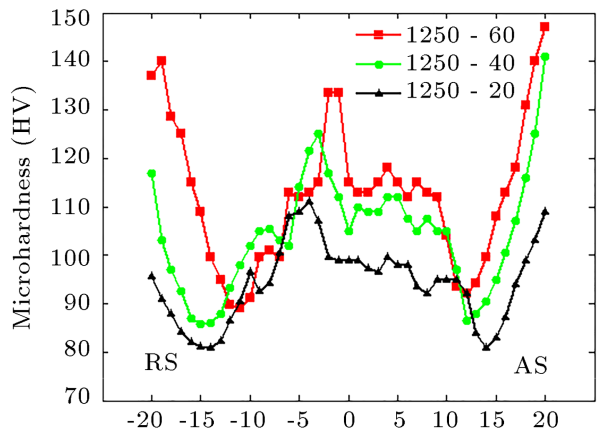

Distance from the weld center $(\mathrm{mm})$

(a)

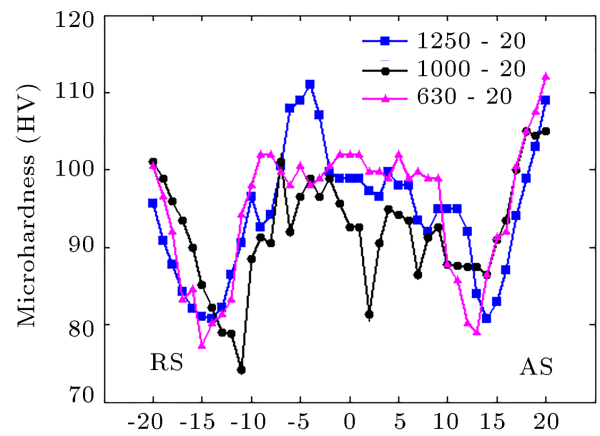

Distance from the weld center $(\mathrm{mm})$

(b)

Figure 6. Microhardness variations in the zones of samples welded at (a) a constant rotational rate of $1250 \mathrm{rpm}$ and different welding speeds, and (b) a constant welding speed of $20 \mathrm{~mm} / \mathrm{min}$ and different rotational rates (RS: Retreating Side, AS: Advancing Side).

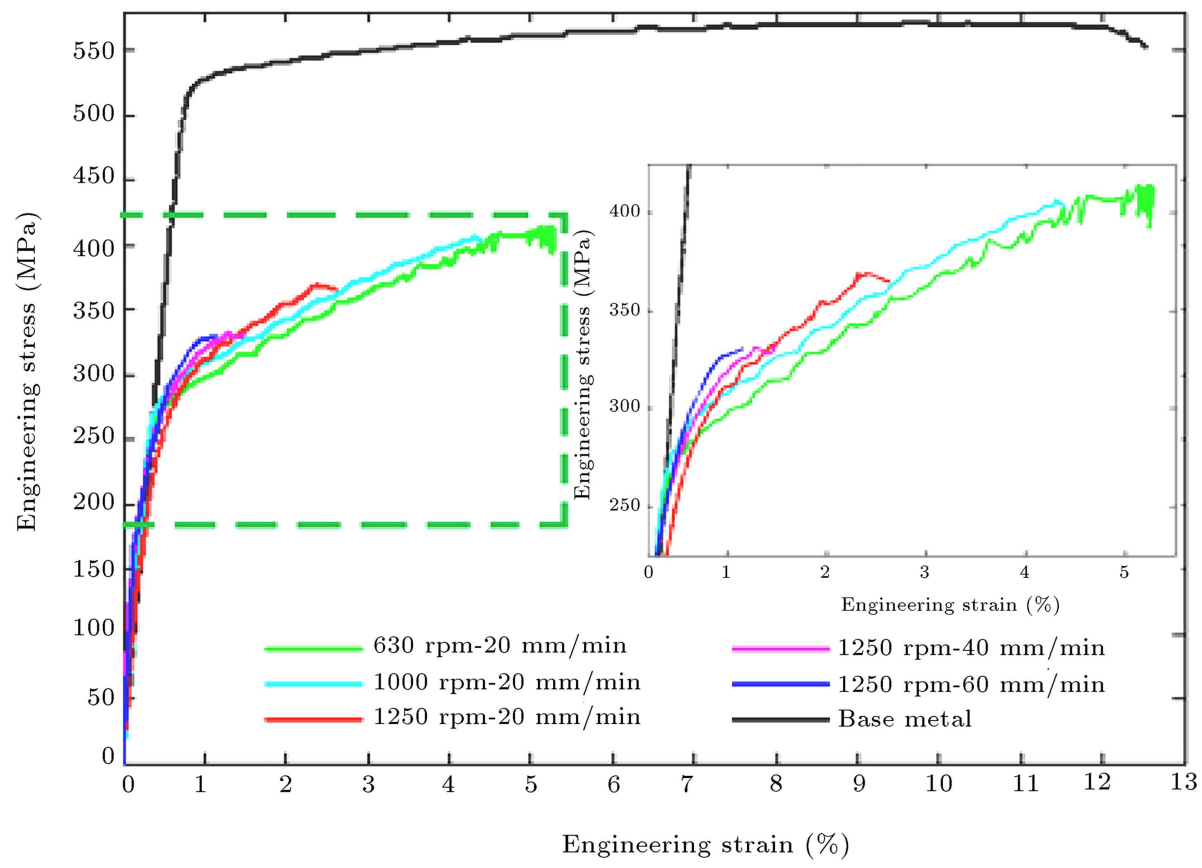

Figure 7. The engineering strain-stress diagrams of 7075 aluminum alloy and the as-welded samples. 

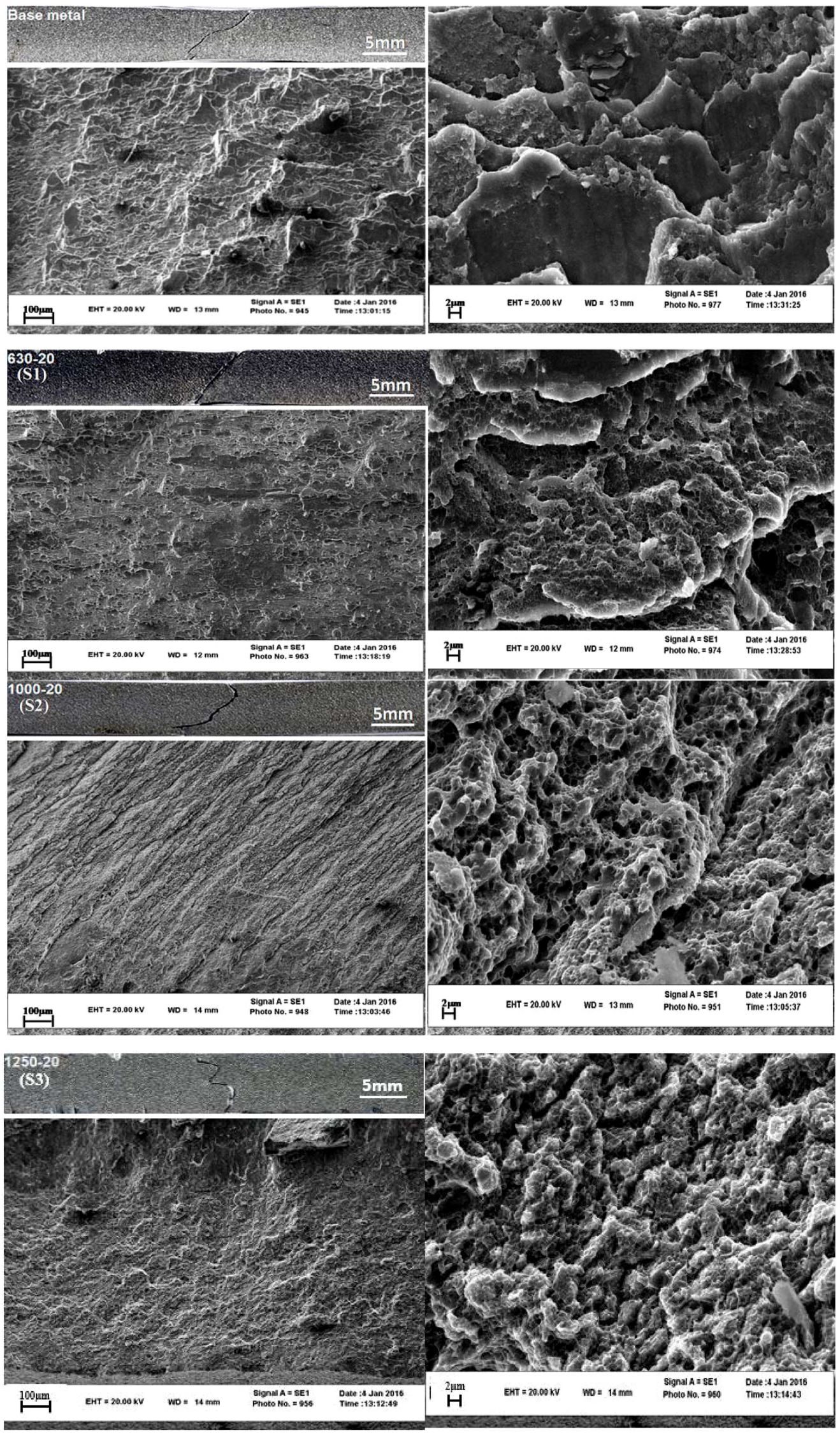

Figure 8. SEM fractographs of 7075 aluminum alloy and the as-welded samples. 
Table 4. Mean grain size, hardness, yield stress, tensile strength, and elongation of the different samples investigated in this study.

\begin{tabular}{cccccc}
\hline $\begin{array}{c}\text { Sample } \\
\text { no. }\end{array}$ & $\begin{array}{c}\text { Mean grain size in } \\
\text { WNZ }(\boldsymbol{\mu m})\end{array}$ & $\begin{array}{c}\text { Mean hardness of } \\
\text { WNZ }(\mathbf{H V})\end{array}$ & $\begin{array}{c}\text { Yield stress } \\
(\mathbf{M P a})\end{array}$ & $\begin{array}{c}\text { Ultimate stress } \\
(\mathbf{M P a})\end{array}$ & $\begin{array}{c}\text { Elongation } \\
(\boldsymbol{\%})\end{array}$ \\
\hline Base metal & - & - & 526.5 & 570.2 & 12.53 \\
S1 & 4.4 & 102 & 295.7 & 405.7 & 5.27 \\
S2 & 5 & 95 & 288.5 & 401 & 4.39 \\
S3 & 5.8 & 98 & 286.2 & 364.8 & 2.62 \\
S4 & 4 & 109 & 301.2 & 332.4 & 1.49 \\
S5 & 3.7 & 113 & 306.2 & 330.4 & 1.15 \\
\hline
\end{tabular}

\section{Conclusion}

The microstructure, defects, and mechanical properties of FSW joints made of AA7075-T651 aluminum alloy plates were studied. The main conclusions are listed below:

1. During the FSW process, weld heat affected the microstructure of the weld zones through the dissolution of precipitates, porosity creation, grain growth, and also the change of the grain structures;

2. Due to the effects of heat input, higher rotational rates or lower welding speeds increased the average grains size of the WNZ and TMAZ areas;

3. FSW at higher rotational rates and higher welding speeds led to the generation of tunneling, cavity, and crack defects in the WNZ-TMAZ interface, making the interface prone to failure;

4. Tool rotational speed must be low enough to facilitate material flow and be high enough to increase the frictional heat in the weld zone. Therefore, defect-free WNZ-TMAZ interfaces could be obtained through the FSW process at a rotational speed of $1000 \mathrm{rpm}$ and a welding speed of 20 $\mathrm{mm} / \mathrm{min}$;

5. Grain growth and precipitates dissolution in the heat-affected weld zones led to decreased microhardness from BM to WNZ areas;

6. In agreement with Hall-Petch strengthening mechanism, higher rotational rates and lower welding speeds led to grain growth in the WNZ area and decreased yield stress and microhardness values;

7. Ultimate tensile strength increased in the case of the sample welded at lower rotational rates, yet decreased for those welded at higher welding speeds due to the creation of crack and tunneling defects in WNZ-TMAZ interfaces;

8. Lower elongation of joint (1.15-5.27\%) compared to base metal could be related to the presence of cracks, tunneling, and microcavity defects in the WNZ-TMAZ interfaces and subsequent stress localization in those regions;
9. Decreasing the rotational rate led to a decrease in the number of deep, shallow, and shared dimples in the SEM fractographs of joint and transferred the ductile fracture mechanism to the combined ductilebrittle mechanism.

\section{Acknowledgments}

The authors would like to appreciate the sincere cooperation of Mr. K. Kolahsangiani (fatigue and fracture lab, Ferdowsi University of Mashhad) and Mrs. M. Hooshyar Sadeghian (electron microscopy research core, FUM central lab).

\section{References}

1. Thomas, W.M., Nicholas, E.D., Needham, J.C., Murch, M.G., Templesmith P., and Dawes, C.J. "Friction stir welding", G.B. Patent 9125978.8 (1991).

2. Cavaliere, P. and Squillace, A. "High temperature deformation of friction stir processed 7075 aluminium alloy", Materials Characterization, 55(2), pp. 136-142 (2005).

3. Cabibbo, M., McQueen, H.J., Evangelista, E., Spigarelli, S., Di Paola, M., and Falchero, A. "Microstructure and mechanical property studies of AA6056 friction stir welded plate", Materials Science and Engineering: A, 460, pp. 86-94 (2007).

4. Mishra, R.S. and Ma, Z.Y. "Friction stir welding and processing", Mater Sci. Eng. R, 50, pp. 1-78 (2005).

5. Balasubramanian, V., Ravisankar. V., and Reddy, G.M. "Influences of pulsed current welding and post weld aging treatment on fatigue crack growth behaviour of AA7075 aluminium alloy joints", International Journal of Fatigue, 30(3), pp. 405-416 (2008).

6. Rafi, H.K., Ram, G.J., Phanikumar, G., and Rao, K.P. "Microstructure and tensile properties of friction welded aluminum alloy AA7075-T6", Materials \& Design, 31(5), pp. 2375-2380 (2010).

7. Sharma, C., Dwivedi, D.K., and Kumar, P. "Effect of welding parameters on microstructure and mechanical properties of friction stir welded joints of AA7039 aluminum alloy", Materials \& Design, 36, pp. 379-390 (2012). 
8. Rajakumar, S., Muralidharan, C., and Balasubramanian, V. "Predicting tensile strength, hardness and corrosion rate of friction stir welded AA6061-T 6 aluminium alloy joints", Materials \& Design, 32(5), pp. 2878-2890 (2011).

9. Mahmoud, T., Gaafer, A., and Khalifa, T. "Effect of tool rotational and welding speeds on microstructural and mechanical characteristics of friction stir welded A319 cast Al alloy", Materials Science and Technology, 24(5), pp. 553-559 (2008).

10. Xue, P., Xie, G., Xiao, B., Ma, Z., and Geng, L. "Effect of heat input conditions on microstructure and mechanical properties of friction-stir-welded pure copper", Metallurgical and Materials Transactions A, 41(8), pp. 2010-2021 (2010).

11. Ghorbanzade, T., Soltanipour, A., Dehghani, K., and Chabok, A. "Microstructural evolutions and mechanical properties of friction stir welded AA2024-3", Proceedings of the Institution of Mechanical Engineers, Part L: Journal of Materials Design and Applications, 230(1), pp. 75-87 (2016).

12. Barenji, R.V. "Effect of tool traverse speed on microstructure and mechanical performance of friction stir welded 7020 aluminum alloy", Proceedings of the Institution of Mechanical Engineers, Part L: Journal of Materials Design and Applications, 230(2), pp. 1-11 (2016).

13. Ren, S., Ma, Z., and Chen, L. "Effect of initial butt surface on tensile properties and fracture behavior of friction stir welded Al-Zn-Mg-Cu alloy", Materials Science and Engineering: A, 479(1), pp. 293-299 (2008).

14. Palanivel, R., Laubscher, R., Dinaharan, I., and Murugan, N. "Tensile strength prediction of dissimilar friction stir-welded AA6351-AA5083 using artificial neural network technique", Journal of the Brazilian Society of Mechanical Sciences and Engineering, 38(6), pp. 16471657 (2016).

15. Li, B., Shen, Y., and Hu, W. "The study on defects in aluminum 2219-T6 thick butt friction stir welds with the application of multiple non-destructive testing methods", Materials \& Design, 32(4), pp. 2073-2084 (2011).

16. Hou, X., Yang, X., Cui, L., and Zhou, G. "Influences of joint geometry on defects and mechanical properties of friction stir welded AA6061-T4 T-joints", Materials \& Design, 53, pp. 106-117 (2014).

17. Chen, H.B., Yan, K., Lin, T., Chen, S.B., Jiang, C.Y., and Zhao, Y. "The investigation of typical welding defects for 5456 aluminum alloy friction stir welds", Materials Science and Engineering: A, 433(1), pp. 6469 (2006).

18. Shojaeefard, M.H., Behnagh, R.A., Akbari, M., Givi, M.K.B., and Farhani, F. "Modelling and Pareto optimization of mechanical properties of friction stir welded AA7075/AA5083 butt joints using neural network and particle swarm algorithm", Materials \& Design, 44, pp. 190-198 (2013).
19. Roshan, S.B., Jooibari, M.B., Teimouri, R., Asgharzadeh-Ahmadi, G., Falahati-Naghibi, M., and Sohrabpoor, H. "Optimization of friction stir welding process of AA7075 aluminum alloy to achieve desirable mechanical properties using ANFIS models and simulated annealing algorithm", The International Journal of Advanced Manufacturing Technology, 69(5-8), pp. 1803-1818 (2013).

20. Sevvel, P. and Jaiganesh, V. "Characterization of mechanical properties and microstructural analysis of friction stir welded AZ31B Mg alloy thorough optimized process parameters", Procedia Engineering, 97, pp. 741-751 (2014).

21. Fuller, C.B., Mahoney, M.W., Calabrese, M., and Micona, L. "Evolution of microstructure and mechanical properties in naturally aged 7050 and $7075 \mathrm{Al}$ friction stir welds", Materials Science and Engineering: A, 527(9), pp. 2233-2240 (2010).

22. Sharma, C., Dwivedi, D.K., and Kumar, P. "Effect of post weld heat treatments on microstructure and mechanical properties of friction stir welded joints of Al-Zn-Mg alloy AA7039", Materials \& Design, 43, pp. 134-143 (2013).

23. Shah, P. and Badheka, V. "An experimental investigation of temperature distribution and joint properties of Al 7075 T651 friction stir welded aluminium alloys", Procedia Technology, 23, pp. 543-550 (2016).

24. Rao, T.S., Reddy, G.M., and Rao, S.K. "Microstructure and mechanical properties of friction stir welded AA7075-T651 aluminum alloy thick plates", Transactions of Nonferrous Metals Society of China, 25(6), pp. 1770-1778 (2015).

25. A. E-112, Standard Test Methods for Determining Average Grain Size, ASTM International USA (2010).

26. Hao, H.L., Ni, D.R., Huang, H., Wang, D., Xiao, B.L., Nie, Z.R., and Ma, Z.Y. "Effect of welding parameters on microstructure and mechanical properties of friction stir welded Al-Mg-Er alloy", Materials Science and Engineering: A, 559, pp. 889-896 (2013).

27. Fratini, L. and Buffa, G. "CDRX modelling in friction stir welding of aluminium alloys", International Journal of Machine Tools and Manufacture, 45(10), pp. 1188-1194 (2005).

28. McNelley, T.R., Swaminathan, S., and Su, J.Q. "Recrystallization mechanisms during friction stir welding/processing of aluminum alloys", Scripta Materialia, 58(5), pp. 349-354 (2008).

29. Frigaard, $\varnothing$., Grong, $\varnothing$., and Midling, O.T. "A process model for friction stir welding of age hardening aluminum alloys", Metallurgical and Materials Transactions A, 32(5), pp. 1189-1200 (2001).

30. Kim, Y.G., Fujii, H., Tsumura. T., Komazaki, T., and Nakata, K. "Three defect types in friction stir welding of aluminum die casting alloy", Materials Science and Engineering: A, 415(1-2), pp. 250-254 (2006).

31. Rajakumar, S., Muralidharan, C., and Balasubramanian, V. "Influence of friction stir welding process and 
tool parameters on strength properties of AA7075-T6 aluminium alloy joints", Materials \& Design, 32(2), pp. 535-549 (2011).

32. Ren, S.R., Ma, Z.Y., and Chen, L.Q. "Effect of initial butt surface on tensile properties and fracture behavior of friction stir welded Al-Zn-Mg-Cu alloy", Materials Science and Engineering: A, 479(1-2), pp. 293-299 (2008).

33. Sivaraj, P., Kanagarajan, D., and Balasubramanian, V. "Effect of post weld heat treatment on tensile properties and microstructure characteristics of friction stir welded armour grade AA7075-T651 aluminium alloy", Defence Technology, 10(1), pp. 1-8 (2014).

34. Callister, W.D. and Rethwisch, D.G., Fundamentals of Materials Science and Engineering: An Integrated Approach, John Wiley \& Sons (2012).

35. Colligan K. "Material flow behavior during friction stir welding of aluminum", Weld J, 78(7), pp. 14-6 (1999).

36. Xu, W., Jinhe Liu, J., Luan, G., and Dong, C. "Temperature evolution, microstructure and mechanical properties of friction stir welded thick 2219-O aluminum alloy joints", Materials and Design, 30, pp. 1886-1893 (2009).

37. Xu, W., Jinhe Liu, J., Luan, G., and Dong, C. "Microstructure and mechanical properties of friction stir welded joints in 2219-T6 aluminum alloy", Materials and Design, 30, pp. 3460-3467 (2009).

38. Chowdhury, S.M., Chen, D.L., Bhole, S.D., and Cao, $\mathrm{X}$. "Tensile properties of a friction stir welded magnesium alloy: Effect of pin tool thread orientation and weld pitch", Materials Science and Engineering: A, 527(21-22), pp. 6064-6075 (2010).
39. Liu, H.-J., Zhang, H.-J., Huang, Y.-X., and Yu, L. "Mechanical properties of underwater friction stir welded 2219 aluminum alloy", Transactions of Nonferrous Metals Society of China, 20(8), pp. 1387-1391 (2010).

\section{Biographies}

Jafar Langari is currently a PhD Student of Mechanical Engineering at the Department of Mechanical Engineering at Ferdowsi University of Mashhad, Iran. He was born in September 20, 1977 in Bojnurd, North Khorasan, Iran. He received his BSc degree in Mechanical Engineering from Ferdowsi University of Mashhad, Iran (2001) and his MSc degree in Automotive Engineering from Iran University of Science and Technology (2004). His main research interests are welding, artificial neural networks, and optimization.

Farhad Kolahan is an Associate Professor at the Department of Mechanical Engineering at Ferdowsi University of Mashhad, Iran. He was born in September 1965 in Mashhad, Iran. He received his BSc degree in Production and Manufacturing Engineering from Tabriz University, Iran. He then continued his postgraduate studies abroad and graduated with a PhD degree in Industrial and Manufacturing Engineering from Ottawa University, Canada in 1999. Dr. Kolahan's research interests include welding, production planning and scheduling, manufacturing processes optimization, and applications of heuristic algorithms in industrial optimization. 